Journal of Case Reports 2018;8(3):208-210

\title{
Pulmonary Dynamics in a Ventilated Breast Cancer Patient
}

\author{
Türkay Akbaş ${ }^{1}$, Perihan Yağci ${ }^{1}$, Aslıhan Yalçın², Ömer Önbaş ${ }^{3}$ \\ Departments of ${ }^{1}$ Internal Medicine and ${ }^{3}$ Radiology, School of Medicine, Düzce University, Düzce, Turkey; ${ }^{2}$ Department of \\ Anesthesiology, Haseki Training and Research Hospital, Istanbul, Turkey.
}

\section{Corresponding Author: \\ Dr. Türkay Akbaş}

Email: turkayakbas@yahoo.com

This is an Open Access article distributed under the terms of the Creative Commons Attribution License (creativecommons.org/ licenses/by/3.0).

Received

Accepted

Published

March 20, 2017

July 18,2018

September 5, 2018

\begin{abstract}
Background: Pulmonary mechanics should be followed regularly in order to reveal lungrelated pathologies and equipment-related technical problems in mechanically ventilated patients. Case Report: We report a patient with breast cancer who was admitted to the intensive care unit after endotracheal intubation. Her pulmonary mechanics showed extremely high airway resistance (Raw) and low dynamic compliance (Cdyn). The patient had no signs of bronchoconstriction, chest or lung stiffness and secretion. The endotracheal tube was exchanged due to kinging at $16 \mathrm{~cm}$, but Raw and Cdyn did not return to normal limits. Chest computed tomography showed the compression of the right main and left lower posterior bronchus by metastatic masses. Abnormally high Raw was attributed to the narrowing of centrally located bronchi, and low Cdyn was connected with unequal distribution of airflow across the lungs due to patchy compressed large airways. Conclusion: Our purpose with this case report is to point out the importance of pulmonary dynamics in artificially ventilated patients.
\end{abstract}

Keywords: Airway Resistance, Breast Neoplasms, Intensive Care Units, Respiratory Physiological Phenomenon, Tomography.

\section{Introduction}

Respiratory mechanics can easily be measured in mechanically ventilated patients. They give clues about diseases affecting lungs and chest walls, and also help us to measure the effects of therapy $[1,2]$. Lung compliance, which is low in patients with massive ascites and pulmonary edema, is noticed to be increasing gradually as patients have effective diuresis. Airway resistance is generally high in case of bronchospasm, but a reduction in resistance is observed after successful bronchodilator therapy. Here, we will present a patient with abnormal lung mechanics who had some diagnostic tests to understand the cause of the abnormal test results.

\section{Case Report}

A 34-year-old woman with breast cancer, who had her last chemotherapy five days ago due to newly diagnosed lung metastasis, was referred to the intensive care unit from the emergency service after intubation. She had uncomfortable breathing and needed high inspiratory pressure level for having a tidal volume of $\geq 200 \mathrm{ml}$. Therefore, she was sedated. Physical examination revealed normal body mass index with no chest wall abnormality and decreased breath sounds on right chest with no wheezing. Pulmonary mechanics on pressure-controlled ventilation showed extremely high airway resistance (Raw) and very low dynamic compliance (Cdyn) [Fig.1]. Peak inspiratory pressure, Pplato and mean airway pressure were 23,20 and $12 \mathrm{~cm} \mathrm{H}_{2} \mathrm{O}$, respectively, which were normal, and $\mathrm{PO}_{2} / \mathrm{FiO}_{2}$ ratio was 290 . Her antero-posterior chest radiography showed a big right paratracheal lesion and the endotracheal tube was just above the right main bronchus. The endotracheal tube was withdrawn back $2 \mathrm{~cm}$, but no change in pulmonary mechanics was perceived. The difficulty in pushing aspiration tube through 
the endotracheal tube was noted by the nurse one hour later. The tube was exchanged and a kink was noticed at the level of $16 \mathrm{~cm}$. After the tube exchange, the Raw decreased from 62 to $37 \mathrm{mbar} / \mathrm{L} / \mathrm{second}$ (1mbar:1.0197 cm $\mathrm{H}_{2} \mathrm{O}$ ), which was still very high, and no meaningful change in Cdyn was observed. A chest computed tomography (CT) taken on the same day demonstrated a big mass extending from the right lung apex to the hilum, compressing the right main bronchus extensively and also another metastatic mass squeezing the left lower posterior bronchus [Fig.2-3]. No signs of major parenchymal infiltration and endobronchial lesion were noticed except small bilateral pleural effusion. Then, abnormal lung mechanics of the patient were considered to be related to the compression of the bronchi by the metastatic masses.

\section{Discussion}

Pulmonary compliance is defined as the change in lung volume per unit with change in pressure. Normal lung compliance ranges between 50-100 $\mathrm{ml} / \mathrm{cm} \mathrm{H}_{2} \mathrm{O}$. Below $40 \mathrm{ml} / \mathrm{cm} \mathrm{H}_{2} \mathrm{O}$ is considered to be a stiffed lung [1]. Reduced compliance can be caused by a stiff chest wall like obesity, ascites, neuromuscular weakness and kyphoscoliosis or a stiffed lung parenchyma which is caused by pulmonary edema or fibrosis, acute respiratory distress syndrome and pneumothorax, which were not present in our patient [2]. Dynamic compliance can also decrease due to non-uniform constriction of distributing airways without parenchymal abnormalities as seen in our patient [3]. In this state, some parts of the lungs supplied by the open airways will be over-distended compared to the parts of the lungs accessed by the narrowed airways. At the end of inspiration, when airflow is ceased, some airflow from over-distended units to the under-distended units will happen and this will cause pressure drops across the entire lungs. Since the compliance is to be calculated during dynamic cycling of maldistributed airflow across the lungs, the computed compliance will be low. In contrast, static compliance does not change, as in our case,

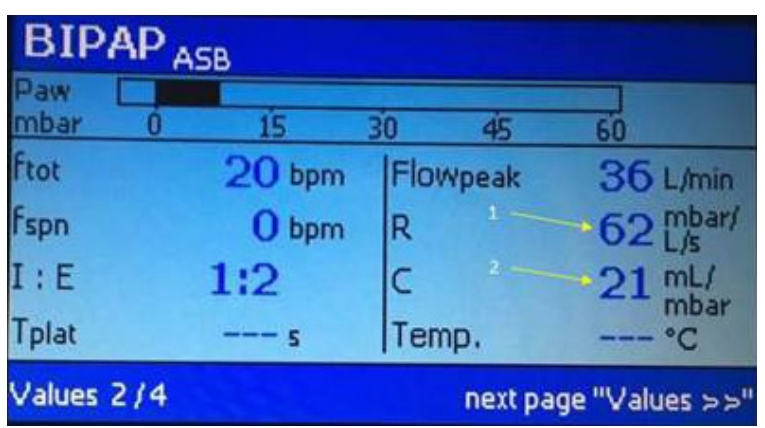

Fig.1: Figure showing high Raw (arrow 1) and low Cdyn (arrow 2) in pressure-controlled mechanical ventilation mode.
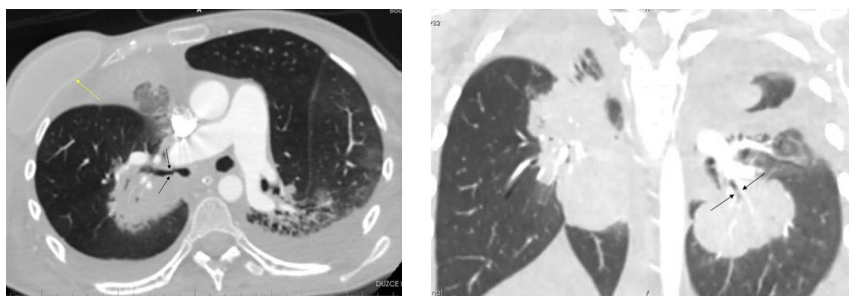

Fig.2,3: Axial and coronal parenchymal images of chest CT showing the compression of the right main bronchus (arrows) and the left lower bronchus (arrows) in the multiple lobular masses. Yellow arrow is showing the right breast prosthesis.

since lung parenchyma is not involved and Raw does not affect airflow during expiration.

Raw is the force opposing airflow in the airways. It depends on the radius and length of the airway and also viscosity of the gas. The most important variable is the radius of the airway and central airways are responsible for the $90 \%$ of total computed Raw [3]. Therefore, the measurement of Raw is more sensitive to the changes in large airways than it is to those in small ones. As the airway lumen decreases, resistance to airflow increases, well known in patients with asthma and chronic obstructive pulmonary disease in which airway inflammation and bronchospasm are the causes of airway narrowing. In normal person, Raw is between $0.5-2.5 \mathrm{~cm} \mathrm{HO}_{2} / \mathrm{L} /$ second [4]. Normal limits are accepted between $5-10 \mathrm{~cm}$ $\mathrm{HO}_{2} / \mathrm{L} /$ second in intubated patients and it rarely exceeds $15 \mathrm{~cm} \mathrm{H}_{2} \mathrm{O} / \mathrm{L} /$ second $[2,4,5]$. The reasons of increased Raw should be investigated. The main 
cause is the bronchial narrowing by bronchial spasm, bronchial edema and presence of secretion in trachea or bronchi which were not detected in our patient. Other reasons are intubation by smallsized tube, endotracheal tube kinking, intubation of the main stream bronchus, granulation tissues at the tip of the tube and other causes of bronchial narrowing. Considering our patient, first we withdrew the intubation tube back as it was located just above the right main bronchus orifice, but Raw did not change. Then, a kink was noticed and the tube was exchanged with a new tube, sized $8.5 \mathrm{~mm}$ which was large enough not to cause iatrogenic resistance. After the tube exchange, Raw did not become normal. Then, CT showed patchy compressions of centrally distributed airways. Subsequently, the high Raw was attributed to the bronchial compression by metastatic masses. The low Cdyn was connected with unequal distribution of airflow across the lungs due to patchy narrowing of the central airways.

\section{Conclusion}

Pulmonary mechanics should be followed regularly in intubated patients and any abnormal parameters should be investigated. If the reason of abnormal measures is detected, then accordingly, the clinician can decide about what should be done later.

Contributors: TA, PY: manuscript writing, patient management; AY: manuscript editing, patient management; OO: critical inputs into the manuscript. TA will act as guarantor. All authors approved the final version of this manuscript.

Funding: None; Competing interests: None stated.

\section{References}

1. Frazer MJ, Lanken P. Approach to mechanical ventilation. In: Lanken P, Manaker S, Kohl B, Hanson $\mathrm{CW}$ (ed). The Intensive Care Unit Manual. $2^{\text {nd }}$ ed. Philadelphia:Elsevier;2014. pp.14-30.

2. Grinnan DC, Truwit JD. Clinical review: respiratory mechanics in spontaneous and assisted ventilation. Crit Care. 2005;9:472-474.

3. Drazen JM. Physiological basis and interpretation of indices of pulmonary mechanics. Environ Health Perspect. 1984;56:3-9.

4. Sakai T, Yoshida H, Yano H, Takaori M. Measurement of airway resistance in anesthetized and paralyzed subjects: proposal for evaluation of K1 values. J Anesth. 1988;2:139-145.

5. Gentile M.E. Bedside monitoring of pulmonary function. In: Vincent JL, Abraham E, Kochanek P, Moore F, Fink M (ed). Textbook of Critical Care. $7^{\text {th }}$ ed. Philadelphia:Elsevier;2017. pp.163-167. 